\title{
Production of Norway spruce embryos in a temporary immersion system (TIS)
}

\author{
Sakari Välimäki ${ }^{1}$ (1) $\cdot$ Laura Paavilainen $^{1} \cdot$ Mikko Tikkinen $^{1} \cdot$ Frida Salonen ${ }^{1} \cdot$ Saila Varis $^{1} \cdot$ Tuija Aronen $^{1}$
}

Received: 9 April 2019 / Accepted: 17 February 2020 / Published online: 9 March 2020 / Editor: Marie-Anne Lelu-Walter

(C) The Author(s) 2020

\begin{abstract}
Somatic embryogenesis has already been used for Norway spruce (Picea abies (L.) Karst) embling production on a laboratory scale, but automation is needed to increase efficiency and reduce costs. One option to scale up production is mass production in bioreactors. In a series of experiments, a pro-embryogenic mass was propagated using Plantform temporary immersion system bioreactors, and the effect of different aeration cycles, support pad materials, and post-maturation treatments (rinsing and desiccation) on the embryo yield and embling survival after 4 to 6 mo in a greenhouse was tested. Three genotypes were used to test each treatment. The best aeration frequency was 20 min every $4 \mathrm{~h}$, while a lower or higher frequency did not generally improve embryo production. Filter paper on plastic netting was the best support pad material in terms of usability and embryo production (varying from $177 \pm 20$ to $696 \pm 109$ per g pro-embryogenic mass). The separation of the embryos from the undeveloped cell mass by rinsing with sterile water resulted in reduced survival of the emblings. Desiccation treatment on nested plates with the embryos on the inner plate with or without filter paper improved their survival. Bioreactors were laborious to prepare, load, and clean. Improvements in embryo production can be achieved by optimizing the process, but bioreactors based on the requirements of somatic embryogenesis are needed to enable their use in the mass production of Norway spruce emblings.
\end{abstract}

Keywords Somatic embryogenesis $\cdot$ Bioreactors $\cdot$ Picea abies $\cdot$ Maturation $\cdot$ Forest biotechnology

\section{Introduction}

In Finland, the increased planting of Norway spruce (Picea abies (L.) Karst), combined with fluctuant seed yields, has resulted in shortages of improved regeneration material (Haapanen et al. 2017). Fluctuating seed yields are mainly caused by irregular flowering, pests, and pathogens (Himanen 2018). In Finland, Norway spruce seed orchards are currently either at the end of their operational lifespan, or are juvenile and do not produce seed at their full potential (Ruotsalainen 2014; Haapanen et al. 2017; Jansson et al. 2017). In Finland, spruce breeding is carried out as a governmental program, and the price of the bred seed is the same as the price of the non-bred seed.

Sakari Välimäki

sakari.valimaki@luke.fi

1 Natural Resources Institute Finland (Luke), Vipusenkuja 5, 57200 Savonlinna, Finland
Somatic embryogenesis (SE) has emerged as a means to clonally propagate conifers on a large-scale, and could mitigate the shortage of improved seed for forest regeneration (Thompson 2014; Bonga 2016). In the future, multiple breeding goals and new material demands may rise quickly and require more flexible breeding schemes (Ruotsalainen 2014). Increased resilience of forests against the negative effects caused by climate change, which includes increased pest outbreaks, will become more important (Marini et al. 2017). Therefore, resilience is already one of the key breeding goals for the Finnish tree breeding program (Haapanen and Mikola 2008).

The production volume with conventional SE-methods is limited due to the amount of manual labor needed. Embryogenic tissue has to be manually transferred to a new growth medium regularly, and mature somatic embryos and germinants have to be handled individually. Automation and scale up are necessary to achieve cost efficient mass propagation. Temporary immersion system (TIS) bioreactor-based culture solutions may provide the means to achieve this goal (Egertsdotter et al. 2019). Bioreactor-based SE can be utilized for many angiosperm species, which includes coffee (Albarran et al. 2005; Ducos et al. 2007; Etienne et al. 
2010), and tea (Akula et al. 2000). Bioreactor-based SE is also being developed for several forest tree species (Businge et al. 2017). In addition, bioreactor-based Norway spruce SE has been developed by a few companies and research institutions, with special TIS designed for the process (Egertsdotter and Clapham 2015; Salonen et al. 2017; Aidun and Egertsdotter 2018). However, there is not much information available on SE maturation and germination using TIS bioreactors. The conditions within a TIS bioreactor differ from those on a semi-solid medium on a plate. Therefore, refinement and optimization of existing protocols are required to use SE propagation methods in TIS bioreactors (Salonen et al. 2017). Proliferation of the early stages of Norway spruce SE, proembryogenic mass (PEM), and immature embryos can be completed in suspension cultures although for a limited number of genotypes (Boulay et al. 1988; Filonova et al. 2000; Bozhkov et al. 2002). Suspension cultures do not appear to be suitable for maturation, even though success with a limited number of genotypes has been achieved (Gorbatenko and Hakman 2001). Inside a TIS bioreactor, the exposure to a liquid medium and shear stress is more limited than in a suspension culture, and the embryos are placed on a solid support, which could improve their maturation (Sun et al. 2011).

The aim of this study was to test commercially available TIS bioreactors for Norway spruce SE, with a focus on maturation and post-maturation treatments of somatic embryos. Furthermore, the germination ability of embryos, and the acclimatization and early growth of the emblings was followed. The effect of varying conditions within TIS bioreactors and different post-maturation treatments was also evaluated.

It was hypothesized that increased aeration during TIS maturation would improve the embryo production, because relative humidity was observed to be high inside a functioning bioreactor. High water availability has been shown to be harmful for somatic embryo development on semi-solid cultures (Klimaszewska et al. 2000; Morel et al. 2014). Following embryo maturation, desiccation treatment can improve germination of somatic embryos (Lelu et al. 1995; Högberg et al. 2001), and was therefore tested for bioreactor embryos. For additional automation, separating the embryos from PEM in a liquid could be one option (Egertsdotter et al. 2019). Therefore, potential effects of rinsing on embryo germination and development were tested.

\section{Materials and Methods}

Plant material All experiments were conducted with embryogenic cell lines of Norway spruce that were initiated from immature seed embryos following the method of Klimaszewska et al. (2001), as described by Varis et al. (2017). Embryogenic tissue from five different genotypes (14Pa645, 14Pa4623, 14Pa653, 14Pa1606, and 15Pa2015), which were from four different full-sib families were used in the experiments. Four of the genotypes were initiated and cryopreserved in 2014 following the methodology developed by Varis et al. (2017). The embryo productivity of the genotypes was confirmed by counting the good-quality embryos from previous maturations on semi-solid media ( $n=5$ to 8 per genotype), and selected genotypes that showed varying embryo production ability (Table 1) were thawed and proliferated on semi-solid media for the experiment. Genotype 15Pa2015 was initiated in 2015 and subcultured biweekly without cryopreservation, until it was used in the aeration experiment I (physiological age $65 \mathrm{wk}$ ). The genotypes 14Pa645 and $14 \mathrm{~Pa} 4623$ were both $47 \mathrm{wk}$ old at the start of the experiment $\mathrm{I}$, and the genotypes $14 \mathrm{~Pa} 645,14 \mathrm{~Pa} 653$, and $14 \mathrm{~Pa} 1606$ were $22 \mathrm{wk}$ old at the start of the aeration and support pad material experiments II-III.

Growth media composition The culture protocol in the TIS bioreactor was composed of proliferation, pre-maturation, maturation, and post-maturation phases. The proliferation medium consisted of a modified form of Litvay's medium (mLM) (Litvay et al. 1985; Klimaszewska et al. 2001). The sucrose (VWR International, Leuven, Belgium, 3\% w/v) concentration was $1 \%(\mathrm{w} / \mathrm{v})$. The $\mathrm{pH}$ was adjusted to 5.8 prior to autoclaving for $20 \mathrm{~min}$ at $121^{\circ} \mathrm{C}$ (Systec VX-75, Labo Line Oy, Helsinki, Finland). L-glutamine (Merck, Darmstadt, Germany, $500 \mathrm{mg} \mathrm{L}^{-1}$ ) was added by filter sterilization after autoclaving. All of the media in the bioreactors were without a gelling agent. The pre-maturation medium was based on $\mathrm{mLM}$-medium, but did not include any plant growth regulators, and had a lower concentration of L-glutamine, and half the concentration of casein (Sigma-Aldrich, St. Louis, MO, $0.5 \mathrm{~g} \mathrm{~L}^{-1}$ ) compared to the proliferation medium $\left(1 \mathrm{~g} \mathrm{~L}^{-1}\right)$. Polyethyleneglycol (PEG) 4000 (Merck, Darmstadt, Germany, $75 \mathrm{~g} \mathrm{~L}^{-1}$ ), was added to the prematuration medium following the method by Attree et al. (1994), and an increased concentration of sucrose (von Arnold and Hakman 1988). The maturation medium was the same as the pre-maturation medium except for the addition of $24 \mu \mathrm{M}$ of abscisic acid (Sigma-Aldrich) (ABA), which was added to the medium through a filter (pore size $20 \mu \mathrm{m}$ ) after autoclaving. The post-maturation medium had the same composition as the maturation medium, with the exception of an added concentration of $45 \mathrm{~g} \mathrm{~L}^{-1}$ myo-inositol (Sigma-Aldrich, Steinheim, Germany) (Egertsdotter and Clapham 2015).

Proliferation and maturation in bioreactors The production of somatic embryos was tested in a Plantform (Plantform, Lomma, Sweden) TIS bioreactor, which was chosen for the experiments based on the comparison of several commercially available models (Salonen et al. 2017). The Plantform bioreactor has two compartments: the lower compartment is filled with growth medium, and the upper is filled with air. Images and more information on the bioreactor can be found on the 
Table 1. The effect of alternative support pad materials and increased aeration from the 2 nd week of maturation on Picea abies (L.) Karst embryo production from genotypes 14Pa645, 14Pa4623, 14Pa653, $14 \mathrm{~Pa} 1606$, and $15 \mathrm{~Pa} 2015$ (embryos per $1 \mathrm{~g}$ of PEM put into the

\begin{tabular}{|c|c|c|c|c|c|c|c|}
\hline Experiment & Support pad material & Aeration & $14 \mathrm{~Pa} 645$ & $14 \mathrm{~Pa} 653$ & $14 \mathrm{~Pa} 1606$ & $14 \mathrm{~Pa} 4623$ & $15 \mathrm{~Pa} 2015$ \\
\hline I & Metal netting & $20 \mathrm{~min} / 4 \mathrm{~h}$ & $174( \pm 37)$ & - & - & $30(-)$ & $155( \pm 21)$ \\
\hline I & Metal netting & $2 \mathrm{~h} / 4 \mathrm{~h}$ & $6( \pm 4)$ & - & - & $11( \pm 6)$ & $151( \pm 13)$ \\
\hline I & Metal netting & constant & 0 & - & - & Contaminated & Contaminated \\
\hline II and III & Metal netting & $20 \mathrm{~min} / 4 \mathrm{~h}$ & $328( \pm 28)$ & $404( \pm 41)$ & $147( \pm 30)$ & - & - \\
\hline II & Metal netting & $\begin{array}{l}20 \mathrm{~min} / 4 \mathrm{~h}, 2 \mathrm{~h} / 4 \mathrm{~h} \text { from the } \\
2 \mathrm{nd} \text { week of maturation }\end{array}$ & $411( \pm 8)$ & $274( \pm 8)$ & $95( \pm 11)$ & - & - \\
\hline III & Plastic netting + filter paper & $20 \mathrm{~min} / 4 \mathrm{~h}$ & $550( \pm 66)$ & $696( \pm 109)$ & $177( \pm 20)$ & - & - \\
\hline III & Polyureathane foam + filter paper & $20 \mathrm{~min} / 4 \mathrm{~h}$ & $142( \pm 13)$ & $533( \pm 13)$ & $38( \pm 11)$ & - & - \\
\hline II and III & Controls on a semi-solid medium & - & $384( \pm 71)$ & $31( \pm 6)$ & $281( \pm 78)$ & - & - \\
\hline \multicolumn{3}{|c|}{ Prior to bioreactor exp. on a semi-solid medium } & $270( \pm 38)$ & $174( \pm 44)$ & $92( \pm 21)$ & $315( \pm 52)$ & $254( \pm 64)$ \\
\hline
\end{tabular}

bioreactor before the proliferation step, \pm SEM). The embryo production in previous experiments on semi-solid medium used as selection criteria for the genotypes is shown
Plantform website (Welander 2014). Plantform TIS bioreactors along with support pad materials and air filters were autoclaved for $20 \mathrm{~min}$ at $115^{\circ} \mathrm{C}$. The bioreactors were filled with $230 \mathrm{~mL}$ of proliferation medium in aseptic laminar conditions. The embryogenic cell mass (1200 mg), was suspended in $30 \mathrm{~mL}$ of proliferation medium, and poured onto the support (metal netting or filter paper) in the bioreactor basket, at the bottom of the upper compartment (total medium volume $260 \mathrm{~mL}$ ). Aquarium pumps with timers were used to pump filtered air into the bioreactor to raise or lower the medium for irrigation. The bioreactors were kept in the dark, and at $21^{\circ} \mathrm{C}$ throughout the entire cultivation period of $10 \mathrm{wk}$.

The growth medium in the bioreactors was changed by transferring the bioreactor basket into a clean, sterilized bioreactor that was filled with $260 \mathrm{~mL}$ of fresh growth medium. The proliferation phase ( $1 \mathrm{wk})$, was followed by a pre-maturation phase ( $1 \mathrm{wk})$. The maturation phase took $5 \mathrm{wk}$ with one medium change after the second week. The post-maturation phase lasted for $3 \mathrm{wk}$. Control maturations on semi-solid media were performed according to Varis et al. (2017).

Experimental design Managing the inner environment in the bioreactor is possible by altering the frequency of the immersions and aeration. The support pad material also affects the growing conditions. In a series of experiments, the effects of different aeration and support pad materials on embryo maturation were tested (Table 1). These experiments were followed by additional trials that focused on the effects of rinsing the mature embryos, and various storage conditions applied prior to germination (Table 2).

The first aeration experiment (experiment I) started on the 18th of October 2016, and the second aeration (experiment II), and support pad material experiment (experiment III), started on the 14th of February 2017. Embryos produced in experiments II and III were used in the post-maturation cold, rinsing, and desiccation treatment trials (experiment IV).

Experiments I and II: bioreactor aeration trials In both experiments, the embryonic mass was immersed in the growth medium for 2 min at 8-h intervals, and afterwards, the medium was pumped back into the lower compartment. In the reference treatment, the air was also pumped into the upper compartment between the immersions to provide aeration (for 20 min at 4-h intervals). In experiment I, aeration was also increased to $2 \mathrm{~h}$ at 4 -h intervals ( 2 min break during immersion). In experiment II, the effects of increased aeration from the second week of the embryo maturation phase onwards were tested. As a reference treatment, aeration periods of
Table 2. Picea abies (L.) Karst embryo germination rates $(\%)$ from genotypes 14Pa645, $14 \mathrm{~Pa} 653$, and $14 \mathrm{~Pa} 1606$ after different post-maturation treatments

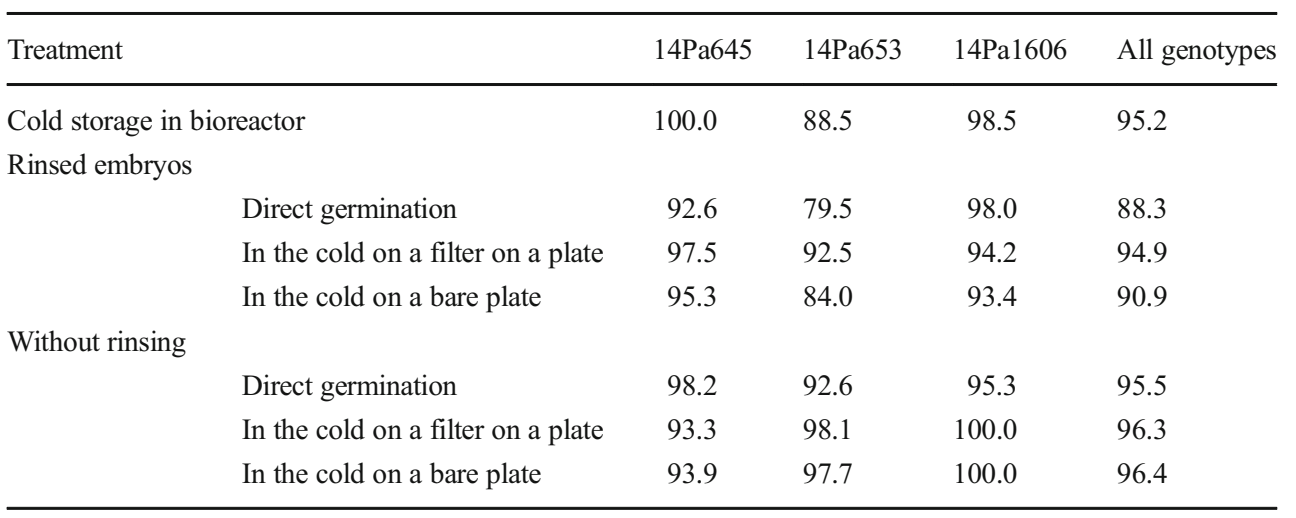


$20 \mathrm{~min}$ at 4-h intervals were used. In all of the aeration experiments, a metal netting was used (mesh size $0.15 \mathrm{~mm}$ ) in the bioreactor basket as the support pad material under the embryogenic mass. Genotypes $14 \mathrm{~Pa} 645,14 \mathrm{~Pa} 4623$, and 15Pa2015 with three bioreactor replicates were used in experiment I, and 14Pa645, 14Pa653, and 14Pa1606 were used in experiment II (Table 1).

Experiment III: support pad material experiment Different support pad materials in the bioreactor basket were tested. The reference treatment consisted of the dense metal netting (mesh size $0.15 \mathrm{~mm}$ ), used in aeration experiments I and II. The bioreactor support pad materials tested in the experiment consisted of a combination of plastic netting (mesh size $1 \mathrm{~cm}$ ) with filter paper (Grade 1300, Munktell Filter AB, Falun, Sweden) and a combination of polyurethane foam ( $1 \mathrm{~cm}$ thick) and filter paper (Grade 1300, Munktell). The immersion time in all treatments was $2 \mathrm{~min}$ at 8 -h intervals, and the aeration time was $20 \mathrm{~min}$ at 4-h intervals. Genotypes 14Pa645, 14Pa653, and $14 \mathrm{~Pa} 1606$ were used in the experiment with three replicates from each genotype. Controls on semi-solid media were completed according to Varis et al. (2017).

Experiment IV: post-maturation treatments For the cold treatment, one bioreactor replicate from each genotype and treatment in aeration, and support pad material experiments II and III, were placed in a dark $+2^{\circ} \mathrm{C}$ environment for $5 \mathrm{wk}$. From the other bioreactor replicates, embryos were given desiccation and rinsing treatments, or germinated directly after maturation.

For rinsing, mature somatic embryos with the accompanying cell mass were collected with a spoon into an Erlenmeyer flask. Sterile water $(200 \mathrm{~mL})$ was poured into the flask, and the flask was rotated to separate the embryos from the undeveloped cell mass. The undeveloped cell mass was discarded and the suspension containing the embryos was poured in small fractions through a Büchner funnel onto filter paper (Whatman \#2, GE Healthcare UK Lmited, Amersham, United Kingdom). Each fraction was rinsed with $10 \mathrm{~mL}$ of sterile water and dried by suction.

Mature embryos from other bioreactor replicates were collected manually, and given two different desiccation treatments. The desiccation treatments for both the rinsed embryos and the ones collected without rinsing were based on the article by Högberg et al. (2001). Up to 25 embryos were placed on a 55-mm Petri plate without a lid, which was placed inside a $90-\mathrm{mm}$ Petri plate filled with $10 \mathrm{~mL}$ of sterile water. The smaller Petri plate was either empty, or had a filter paper (Whatman \#2) moistened with sterilized water on the bottom. The larger Petri plate was sealed with parafilm. Using a modification from Högberg et al. (2001), the Petri plates were transferred to a dark environment with a temperature of + $2{ }^{\circ} \mathrm{C}$ for $5 \mathrm{wk}$, following the recommendations made by
Varis et al. (2017), that cold storage enhances the germination of Norway spruce somatic embryos.

Embryo measurements and germination Embryos grown on filter paper placed on plastic netting were photographed with Zeiss AxioCam ERc 5s, attached to a stereomicroscope (Leica), with a Zeiss Achromat S 0.5x FWD $134 \mathrm{~mm}$ objective at $\times 1$ magnification, after they were arranged on a germination plate. The embryo length, the width of the cotyledons, the width below the cotyledons, the width from the middle section of the embryo, and the width of the root were measured using ImageJ software (version $1.48 \mathrm{v}$; Java 1.8.0_51 [32-bit]) (Svobodová et al. 1999; Tikkinen et al. $2018 \mathrm{~b}$ ). After germination, the same embryos were photographed (Canon Powershot G5), and their root and shoot lengths were measured with the ImageJ software.

In aeration and support pad material experiments II and III, some of the embryos were germinated immediately, and some were germinated after 5-wk cold and desiccation treatments. Depending on embryo production, 7 to 90 embryos per genotype and treatment were germinated on LM-germination medium for $14 \mathrm{~d}$ in $130 \mu \mathrm{mol} \mathrm{m} \mathrm{m}^{-2} \mathrm{~s}^{-1}$ (Valoya L14 spectrum AP67 Milky LED, Valoya Oy, Helsinki, Finland) with an $18 \mathrm{~h} / 6 \mathrm{~h}$ day/night cycle. After germination, they were transplanted to containers filled with peat-based growth media (ViviPak, Gravendeel, Netherlands), and were grown for $21 \mathrm{~d}$ under laser perforated plastic covers in high humidity (over 90\%). After removing the plastic covers, the containers were irrigated daily by mist spraying with TaimiSuperX fertilizer $(0.1 \%$ w/v, Kekkilä Oy, Vantaa, Finland). After $35 \mathrm{~d}$ of openair cultivation, the surviving emblings were transplanted into Plantek 81f containers (81 separate ventilated compartments $85 \mathrm{~cm}^{3}$ in size), filled with pre-fertilized semi-coarse sphagnum peat. Observations on the embryo performance were made around 4 mo after transplantation into the $81 \mathrm{f}$ containers.

Statistical analysis Statistical analyses were carried out using SPSS Version 25 (IBM Corp. Armonk, NY). The normality and homogeneity of variances were checked using Kolmogorov-Smirnov and Levene tests (SPSS, 1999). As the data was not normally distributed, a non-parametric Kruskal-Wallis-test (SPSS, 1999) was used to analyze differences in the embryo yield and survival rates for different aeration treatments, support pad materials, and post-maturation treatments. A probability of $p \leq 0.05$ was considered significant. Differences in the embryo dimensions for different desiccation treatments were analyzed using a Kruskal-Wallis test. Mean values are presented with standard errors $( \pm)$.

Logistic regression $-(\log (p / 1-p))$ was used to investigate the significant factors that affected the embling survival. The genotype covariate was used to investigate the effects of clone variation on the survival. Treatment covariate was used to 
determine the effects of the support pad material and aeration on survival. The post-maturation treatment covariate was used to predict the effects of desiccation and rinsing treatments on the survival of the emblings.

\section{Results}

Effect of increased aeration on embryo production and survival In experiment I, increasing the aeration from $20 \mathrm{~min}$ in $4 \mathrm{~h}$ intervals to $2 \mathrm{~h} / 4 \mathrm{~h}$, decreased embryo yield with genotypes $14 \mathrm{~Pa} 645$ and $14 \mathrm{~Pa} 4625$, and had no effect on genotype 15Pa2015. However, the changes were not statistically significant (Table 1). Constant aeration was significantly worse than $20 \mathrm{~min} / 4 \mathrm{~h}$ aeration $(p<0.01)$, and no mature embryos were produced. In addition, five out of nine bioreactors in the treatment were contaminated.

In experiment II, increasing the duration of aeration in the second week of maturation had a negative effect on the embryo yield for genotypes 14Pa653 and 14Pa1606 (Table 1). Genotype 14Pa645 produced more embryos when the aeration was increased during maturation. The differences between treatments in embryo yield were not statistically significant. However, increased aeration did significantly reduce the survival of the embryos of all genotypes after 4 to 6 mo for all of the genotypes after transplantation (Fig. 1; Table 3).

Effect of the support pad material on embryo production, quality and survival When metal or plastic netting with filter

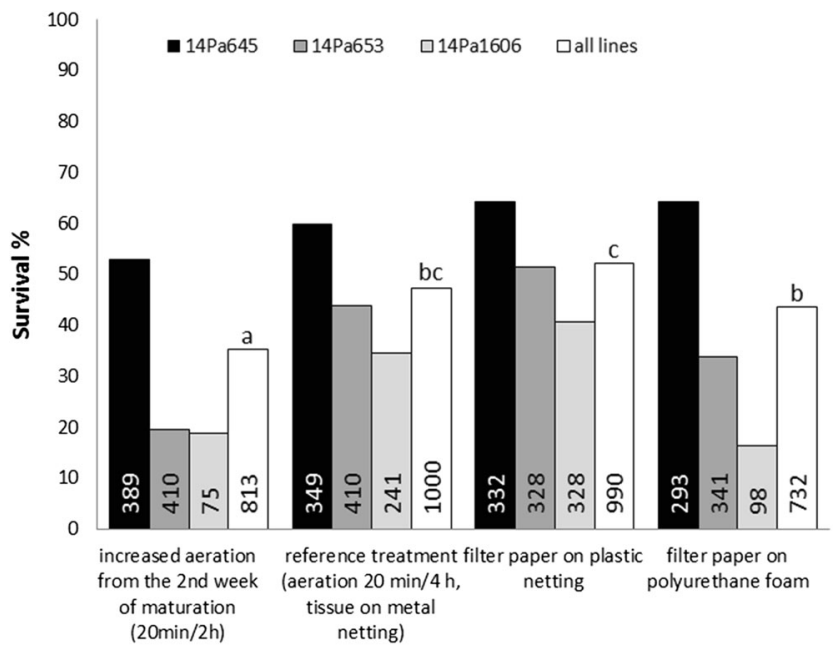

Figure 1. The effect of alternative support pad materials and increased aeration from the $2 \mathrm{nd}$ wk of aeration on the survival of Picea abies (L.) Karst plantlets from genotypes 14Pa645, 14Pa653, and 14Pa1606 at 4 6 mo. Significant differences between the treatments have been marked with small case letters. The total number of embryos at the beginning of germination for each treatment and genotype is presented at the bottom of the bar. The data includes all of the post-maturation treatments, except those that were rinsed, and embryos that germinated directly after maturation have been excluded because the corresponding data was not available for the reference treatment. paper was used as the support pad material, somatic embryos with normal morphology were produced. These embryos were elongated and had well-developed cotyledons (Fig. 2a, b), while embryos developed on polyurethane foam and filter paper had a distinctive appearance. They were short and often had supernumerary cotyledons (Fig. 2cz).

The combination of plastic netting with filter paper produced more embryos for all genotypes compared to metal netting, although the difference in embryo production was not statistically significant. The embryo production was better on metal netting compared to polyurethane foam and filter paper, except for the 14Pa653 genotype (Table 1). Fewer embryos were produced on a semi-solid medium than in bioreactors. However, control maturations on a semi-solid medium with genotype 14Pa653 produced abnormally few embryos (Table 1). Excluding the genotype 14Pa653, more embryos were produced on control plates than in bioreactors, except with filter paper on plastic netting as a support pad. For genotypes 14Pa653 and 14Pa1606, the embryo survival 4 to $6 \mathrm{mo}$ after transplantation was higher for embryos grown on metal netting or on plastic netting with filter paper, than on polyurethane foam with filter paper, but for 14Pa645, the survival rate was the highest with embryos grown on polyurethane foam with filter paper (Fig. 1, Table 3). The differences in survival between treatments within genotypes were not statistically significant. However, the survival of emblings grown on filter paper was significantly higher on plastic netting than on polyurethane foam (Fig. 1).

Effect of rinsing and cold and desiccation treatments on embryo viability and survival The initial embryo germination rates were at least $79.5 \%$ for all of the genotypes and postmaturation treatments (Table 2). The embling survival was evaluated 4 to 6 mo after transplantation. Significant differences were found between the plants subjected to different desiccation treatments at the embryo stage (Fig. 3, Table 3). Plate desiccation in the cold either with or without filter paper increased the survival of the embryos compared to other treatments. Desiccation on filter paper was also significantly better than desiccation without filter paper. On the other hand, rinsing the embryos reduced their survival chances even if they were desiccated.

Dimensions of mature and germinated embryos The embryos grown on filter paper placed on plastic netting (experiment III) were photographed before and after germination. Desiccated embryos from all of the genotypes combined $(2.5 \mathrm{~mm} \pm$ $0.02 \mathrm{~mm}$ ) which were not rinsed were significantly longer than embryos that were germinated directly after maturation without rinsing $(2.3 \mathrm{~mm} \pm 0.03)(p<0.01)$. The desiccated embryos were longer with all of the individual genotypes compared to the directly germinated unrinsed embryos, although the difference was only significant with $14 \mathrm{~Pa} 653$. 


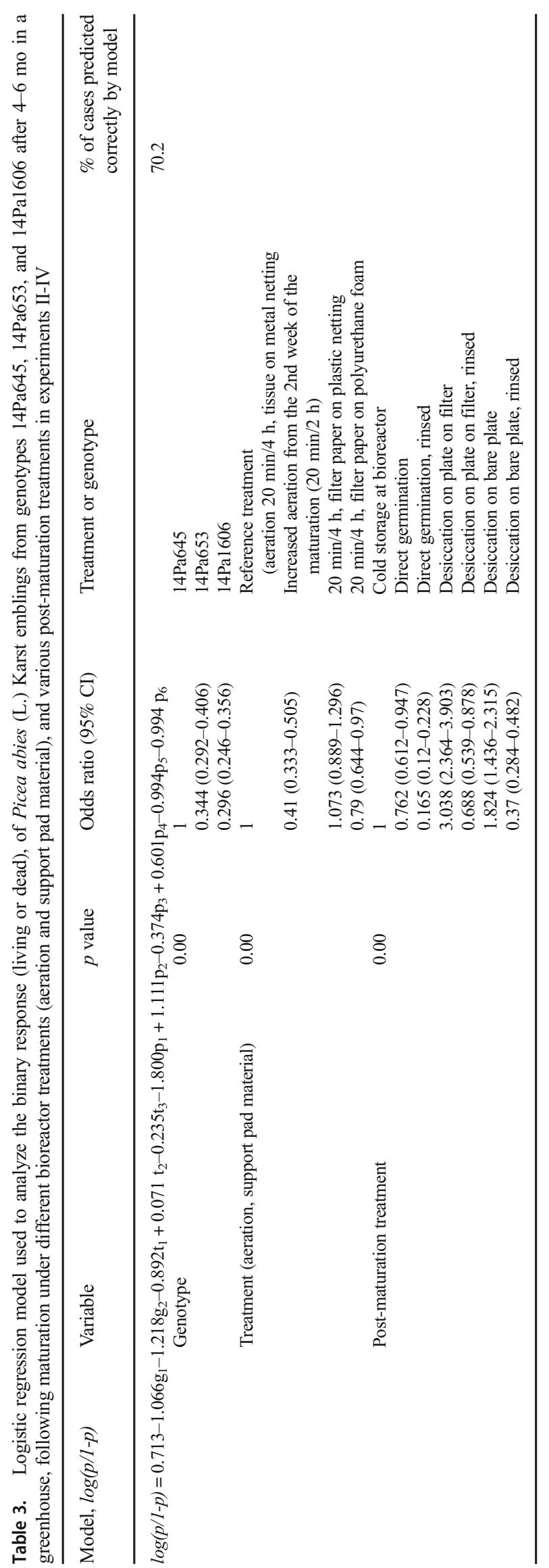

After germination, the root and shoot lengths were measured, and the post-maturation treatment was found to have a significant effect on the embryo shoot and root lengths (Fig. 4). In all of the treatments in which the embryos were rinsed, the shoots were significantly shorter compared to embryos from any other treatments. Significant differences in root length were also found between the desiccation treatments. Directly germinated rinsed embryos produced the shortest roots $(0.11 \mathrm{~cm} \pm 0.02 \mathrm{~cm})$, but the longest roots $(0.63 \mathrm{~cm} \pm$ $0.06 \mathrm{~cm}$ ) were produced by filter desiccated embryos that were also rinsed.

\section{Discussion}

The frequency of bioreactor aeration, and choice of support pad material were found to affect embryo production, and post-maturation treatment also affected embryo survival. Aeration of TIS bioreactors is required for gas exchange and to ventilate the bioreactor. It was hypothesized that the tissue inside the bioreactor remains more moist than might be ideal, and therefore, supplementary aeration could improve embryo production. However, in experiment I, increased aeration reduced embryo production (Table 1) and the survival rate of the plantlets (Fig. 1). Moreover, no mature embryos were produced using constant aeration. The high contamination rate of the bioreactors under constant aeration could be caused by overloading the PET filters with the constant air flow. The effect of increased aeration from the second week of maturation was also tested, because it was hypothesized that moisture would be more harmful at the later stages of maturation. Nevertheless, increased aeration reduced embryo production and survival. Frequent aeration predisposes the embryos to more shear stress, which could hinder embryo development (Bienick et al. 1995; Sun et al. 2010). In a TIS system, pressure caused by aeration is also used to lower the medium surface after irrigation of the culture, and cannot completely be avoided. However, some aeration should be beneficial, because oxygen depletion and ethylene accumulation can compromise the embryo yield (Huang et al. 2006). Based on previous experiments, $20 \mathrm{~min}$ of aeration at 4-h intervals was better for proliferation than the same aeration at either 6- or 8$\mathrm{h}$ intervals (Salonen et al. 2017). The gas composition requirements together with the medium concentration can be highly variable. For example, for Norway spruce maturation, a higher $\mathrm{O}_{2}$ partial pressure stimulates embryo development in a halfstrength LP medium, but inhibits development in a fullstrength medium (Kvaalen and von Arnold 1991).

In experiment III, the largest number of embryos in all of the tested genotypes was produced with filter paper on plastic netting as a support pad material (Table 1). The reason could be that on the plastic netting, the filter paper dries more efficiently between immersions than on polyurethane foam. The 


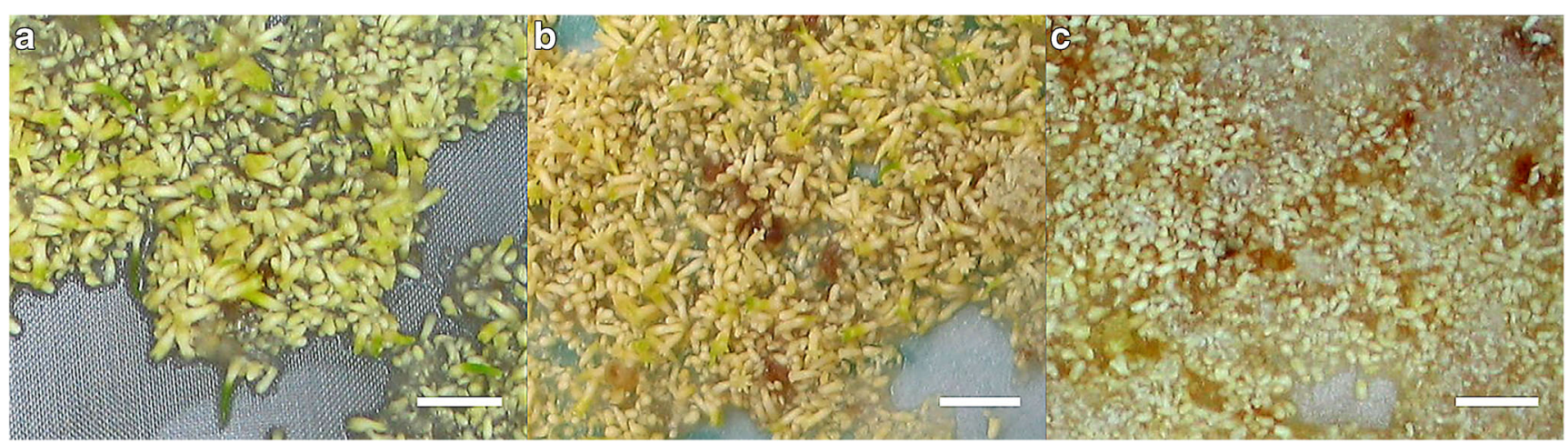

Figure 2. Picea abies (L.) Karst embryos from genotype 14Pa645 that matured on different support pad materials for $6 \mathrm{wk}:(a)$ metal netting; $(b)$ filter paper on plastic netting; $(c)$ filter paper on polyurethane foam. The

metal and the plastic netting did not differ significantly regarding embryo production, but the combination of plastic netting and filter paper was easier to handle. Metal netting was more difficult to place evenly and to clean, and the plastic netting was also more affordable.

Excluding the genotype 14Pa653, the semi-solid medium was second to the bioreactor maturation only when the support pad material consisted of filter paper on plastic netting. On polyurethane foam, the embryos had a distinct morphology and were shorter but also more swollen, which indicated impaired development and excess water intake (Fig. 2c). Excessive water availability during maturation can hinder embryo development and affect survival (Klimaszewska et al. 2000). Embryos that are cold-stored on filter paper on a semi-solid medium develop into emblings with better survival chance than embryos in direct contact with the medium (Tikkinen et al. 2018a).

Embryo production varied depending on the genotype propagated. Some Norway spruce genotypes may be better suited for bioreactor cultivation than others, and their growth during proliferation phase varies (Salonen et al. 2017), which can impact the maturation results, because there was no control of tissue levels photos were taken when the maturation medium was changed to the postmaturation medium (myo-inositol added). The scale bar in each image represents $10 \mathrm{~mm}$.

prior to pre-maturation. In the present study, genotypes also responded to treatments differently. For example, 14Pa645 was not affected as much by increased aeration as the other two genotypes. There is also substantial variation in how well different genotypes produce embryos on semi-solid medium plates, and their physiological age can affect the results (Tikkinen et al. 2018b). The reference treatments with 14Pa645 in experiment I and experiment II/III (aeration $20 \mathrm{~min} / 4 \mathrm{~h}$, metal net) produced very different numbers of embryos. However, contrary to expectations, tissue which had been subcultured longer (47 wk) produced more embryos than more recently thawed material ( $22 \mathrm{wk}$ old). In the experiment III, the maturation on a semi-solid medium failed with genotype 14Pa653. Even though it first appeared to be a good genotype, 14Pa653 has since been excluded from the commercial pilot propagations currently conducted in Finland (Tikkinen et al. 2019), due to its inconsistent embryo yield, as well as genotype 14Pa4623 that was used in aeration experiment I.

With bioreactors, variation in embryo yields was also observed among the replicates. One of the reasons for this is likely that the cell suspension is difficult to spread evenly on the support pad. More even spreading could lead to more synchronized timing of the embryo development and result
Figure 3. The effects of different desiccation and rinsing treatments on the survival of Picea abies (L.) Karst emblings from genotypes $14 \mathrm{~Pa} 645,14 \mathrm{~Pa} 653$, and $14 \mathrm{~Pa} 1606$ at 4-6 mo. Treatments with no significant differences have been marked with the same letters. The total numbers of embryos germinated for each genotype and treatment are shown at the bottom of each bar.

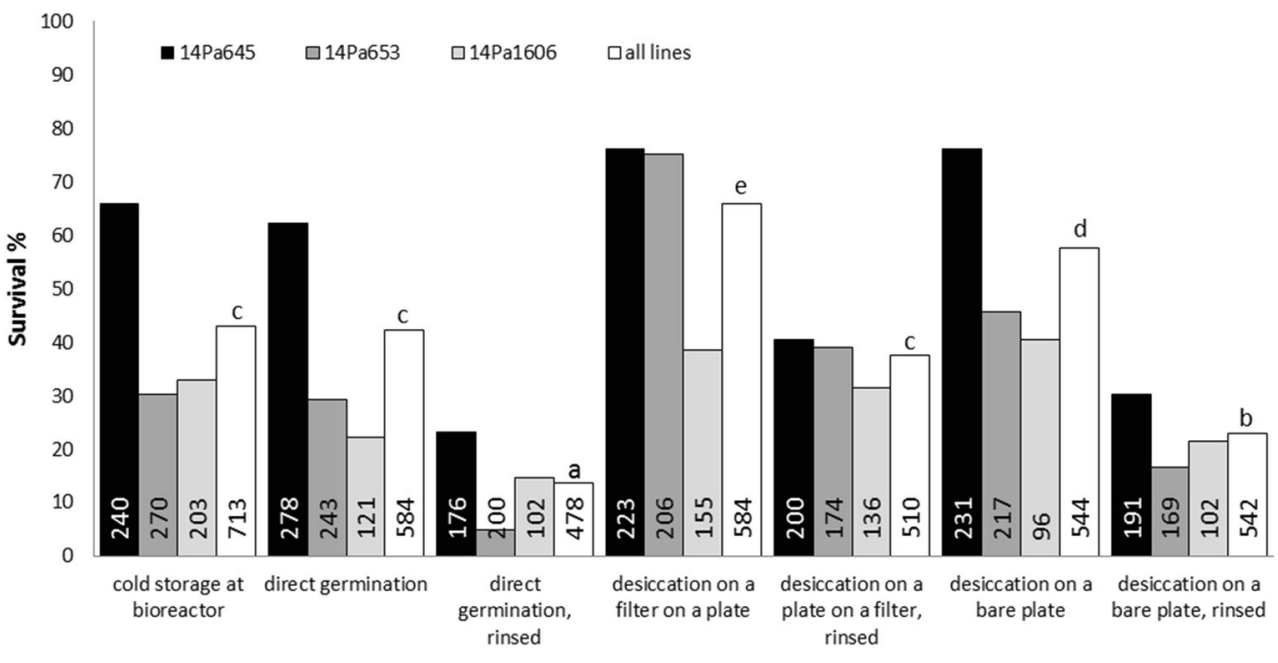


in improved and more consistent embryo yields and survival (Mamun et al. 2018). In addition, PET filters are used and autoclaved multiple times, which could affect the subsequent air flow. This could be a source for variation in conditions in the bioreactors.

The choice of post-maturation treatment together with the genotype was the best predictor for survival, even though maturation conditions also had a significant effect on survival, which could not be explained with the other variables (Table 3 ). Rinsing the embryos with sterile water to separate them from undeveloped tissue reduced the embryo survival (Fig. 3). The procedure predisposes the embryos to shear and osmotic stress, probably more than culture in a liquid medium. Osmotic stress could perhaps be ameliorated by using a less hypotonic solution than water for rinsing, while shear stress could be reduced by using less abrasive rinsing methods. Sterile water was used for rinsing, as it would minimize the extra costs, and is also considered as one option for developed automatic embryo dispersion systems (Aidun and Egertsdotter 2011).

Desiccation improved embling survival, especially when the embryos were desiccated on a moistened filter paper on nested Petri plates (Fig. 3). In the current production routines, the embryos are developed on a filter paper on a semi-solid medium and additional desiccation treatments are not used, but some desiccation is thought to take place during the cold storage of the mature embryos (Varis et al. 2017). For the bioreactor embryos however, desiccation appears to improve the embryo quality. The embryos in bioreactors develop under high humidity and this could necessitate extra desiccation. However, even though it may be beneficial, desiccation adds an extra step, which requires manual labor and increases production costs.

Some significant differences were found between embryos subjected to different desiccation treatments before germination. In comparison to these results, Tikkinen et al. (2018b) found shorter embryos had better survival chances within a given treatment, which was hypothesized as being the result of selection or precocious germination due to sub-optimal cold- storage conditions. According to these results, unrinsed desiccated embryos were longer and had better survival rates than embryos germinated directly after maturation, which indicated that some maturation and growth occurred during desiccation. However, embryo length itself does not explain the increased survival, but the desiccation treatments probably increased the length and physiological capability to survive. However, selection bias for longer or shorter embryos in some treatments cannot be completely ruled out. Significant differences between the treatments were also found in the embryo thickness, which indicated that desiccated embryos could be generally larger than non-desiccated embryos (data not shown). Increased survival after desiccation could be explained by improved lipid accumulation rather than due to the embryo dimensions. According to Attree et al. (1992), lipid biosynthesis is affected by maturation conditions, but continues through desiccation. After germination, significant differences between different treatments were found between the root and shoot lengths (Fig. 4). Rinsed embryos had shorter shoots, but the lengths of the roots varied. Because of the shorter shoot length, their root-shoot ratio was higher, but that did not improve survival. In addition, the measurements of embryos at certain points in their development are only indicative of quality, as they may develop at different rates.

The embryos that were produced in aeration and support pad material experiments II and III were used in the desiccation experiment IV. Therefore, the embryo survival was affected by the genotype, support pad, aeration, and desiccation treatment (Table 3). As there is no established method for bioreactor cultivation, the control treatments are more or less arbitrary. The overall survival of the embryos could have been improved by shorter in vitro germination time, such as for $1 \mathrm{wk}$, as suggested by Tikkinen et al. (2018b). Longer germination was needed to observe differences between the treatments in root and shoot lengths. The overall survival could also have been reduced by the amount of PEG used, as 7.5\% could be too high (Svobodová et al. 1999). Excessive PEG in maturation can compromise the
Figure 4. The effects of different desiccation treatments on the shoot (positive scale) and root (negative scale) lengths of Picea abies (L.) Karst plantlets (14Pa645, 14Pa653, and 14Pa1606 combined) after $2 \mathrm{wk}$ of germination. Treatments with no significant differences have been marked with the same letters. Error bars represent SEM.

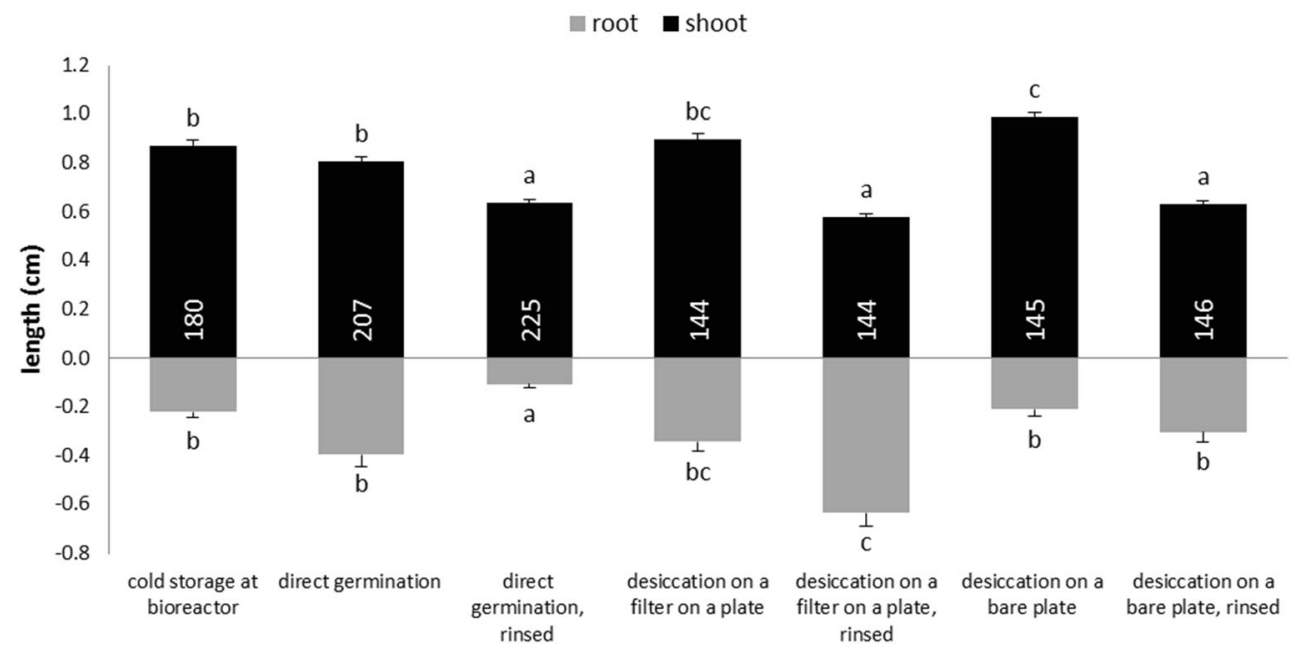


germination and ex vitro performance of emblings (Bozhkov and von Arnold 1998). The ABA concentration was set to $24 \mu \mathrm{M}$ based on results from preliminary maturation experiments. In addition, the sucrose concentration was increased in the maturation medium, which as a plasmolyzing agent could hinder embryo development (Attree et al. 1991).

The Plantform bioreactor has not been designed primarily for SE, but has been for micropropagation, and has been successfully used for the propagation of several plant species through organogenesis (Welander et al. 2014). Therefore, the dimensions of the bioreactor may not be optimal for SE. Considering the costs of propagation, bioreactor durability is also important, as sterilization with an autoclave can result in occasional breaking of the bioreactors or lids. With a large number of bioreactors in rotation, a lot of manual labor was needed for the cleaning, assembly, and sterilization. Therefore, to compare propagation costs in bioreactors versus Petri plates, recording the embryo production against both use of consumables and working hours should be completed with optimized protocols.

For Norway spruce SE, these results demonstrated that both the frequency of bioreactor aeration and the choice of support pad material affected the embryo production and survival. Survival of the emblings can be improved by post-maturation desiccation of the embryos. The best results were achieved when embryo maturation in TIS was performed on filter papers on plastic netting, with $20 \mathrm{~min} / 4 \mathrm{~h}$ aeration, and the mature embryos desiccated at $+2^{\circ} \mathrm{C}$ for $5 \mathrm{wk}$ on nested plates. On the other hand, rinsing the embryos with sterile water to separate them from the PEM reduced their survival. The optimization of the process was complicated by different genotypes which all had different preferences for growth and maturation conditions. This also emphasizes the importance of using a sufficient number of genotypes to test novel protocols for SE.

Acknowledgments We would like to thank Airi Huttunen and Paula Matikainen for their excellent technical assistance, and Eija Matikainen for processing Fig. 2.

Funding information Open access funding provided by Natural Resources Institute Finland (LUKE). The studies were funded by the European Regional Development Fund and Savonlinna municipality within the projects A73586, A72814, and A70606.

Open Access This article is licensed under a Creative Commons Attribution 4.0 International License, which permits use, sharing, adaptation, distribution and reproduction in any medium or format, as long as you give appropriate credit to the original author(s) and the source, provide a link to the Creative Commons licence, and indicate if changes were made. The images or other third party material in this article are included in the article's Creative Commons licence, unless indicated otherwise in a credit line to the material. If material is not included in the article's Creative Commons licence and your intended use is not permitted by statutory regulation or exceeds the permitted use, you will need to obtain permission directly from the copyright holder. To view a copy of this licence, visit http://creativecommons.org/licenses/by/4.0/.

\section{References}

Aidun CK, Egertsdotter U (2011) Method for dispersion of assemblies of biological material. U.S. Patent No. 8,927,287,B2

Aidun CK, Egertsdotter U (2018) SE fluidics system. In: Jain SM, Gupta $\mathrm{P}$ (eds) Step wise protocols for somatic embryogenesis of important woody plants. Springer, pp 211-227

Akula A, Becker D, Bateson M (2000) High-yielding repetitive somatic embryogenesis and plant recovery in a selected tea clone, 'TRI2025', by temporary immersion. Plant Cell Rep 19:1140-1145

Albarran J, Bertrand B, Lartaud M, Etienne H (2005) Cycle characteristics in a temporary immersion bioreactor affect regeneration, morphology, water and mineral status of coffee (Coffea arabica) somatic embryos. Plant Cell Tiss Org Cult 81:27-36

Attree S, Moore D, Sawhney V, Fowke L (1991) Enhanced maturation and desiccation tolerance of white spruce (Picea glauca (Moench) Voss) somatic embryos: effects of a non-plasmolysing water stress and abscisic acid. Ann Bot 68:519-525

Attree S, Pomeroy M, Fowke L (1994) Production of vigorous, desiccation tolerant white spruce (Picea glauca (Moench.) Voss.) synthetic seeds in a bioreactor. Plant Cell Rep 13:601-606

Bienick ME, Harrell RC, Cantliffe DJ (1995) Enhancement of somatic embryogenesis of Ipomoea batatas in solid eultures and production of mature somatic embryos in liquid cultures for application to a bioreactor production system. Plant Cell Tiss Org Cult 41:1-8

Bonga J (2016) Conifer clonal propagation in tree improvement programs. In: YS Park, JM Bonga, HK Moon (eds) Vegetative propagation of forest trees. National Institute of Forest Science (NiFos), Seoul, pp 3-31

Boulay M, Gupta P, Krogstrup P, Durzan D (1988) Development of somatic embryos from cell suspension cultures of Norway spruce (Picea abies Karst.). Plant Cell Rep 7:134-137

Bozhkov PV, Filonova LH, von Arnold S (2002) A key developmental switch during Norway spruce somatic embryogenesis is induced by withdrawal of growth regulators and is associated with cell death and extracellular acidification. Biotechnol Bioeng 77:658-667

Bozhkov PV, von Arnold S (1998) Polyethylene glycol promotes maturation but inhibits further development of Picea abies somatic embryos. Physiol Plant 104:211-224

Businge E, Trifonova A, Schneider C, Rödel P, Egertsdotter U (2017) Evaluation of a new temporary immersion bioreactor system for micropropagation of cultivars of eucalyptus, birch and fir. Forests 8:196

Ducos J, Lambot C, Pétiard V (2007) Bioreactors for coffee mass propagation by somatic embryogenesis. Int J Plant Dev Biol 1:1-12

Egertsdotter U, Ahmas I, Clapham D (2019) Automation and scale up of somatic embryogenesis for commercial plant production, with emphasis on conifers. Frontiers in Plant Sci 10:109

Egertsdotter U, Clapham D (2015) Method for maturing and synchronizing conifer somatic embryos. US Patent No 9:125,352

Etienne H, Bertrand B, Ribas A, Lashermes P, Malo E, Montagnon C, Alpizar E, Bobadilla R, Simpson J, Dechamp E (2010) Current applications of coffee (Coffea arabica) somatic embryogenesis for industrial propagation of elite heterozygous materials in Central America and Mexico. In: Park YS, Bonga JM, Park SY, Moon HK (eds) Proceedings of the IUFRO Working Party 2.09.02: somatic embryogenesis of trees advances in somatic embryogenesis of trees and its application for the future forests and plantations August 19-21, 2010, Suwon, Republic of Korea, pp 59-67

Filonova LH, Bozhkov PV, Brukhin VB, Daniel G, Zhivotovsky B, von Arnold S (2000) Two waves of programmed cell death occur during formation and development of somatic embryos in the gymnosperm, Norway spruce. J Cell Sci 113(Pt 24):4399-4411 
Gorbatenko O, Hakman I (2001) Desiccation-tolerant somatic embryos of Norway spruce (Picea abies) can be produced in liquid cultures and regenerated into plantlets. Int J Plant Sci 162:1211-1218

Haapanen M, Leinonen H, Leinonen K (2017) Männyn ja kuusen siemenviljelyssiemenen taimitarhakäytön kehitys 2006-2016: Alueellinen tarkastelu. Metsätieteen Aikakauskirja 2017

Haapanen M, Mikola J (2008) Metsänjalostus 2050 - pitkän aikavälin metsänjalostusohjelma. Working Papers of the Finnish Forest Research Institute 71

Himanen K (2018) Seed quality attributes in seedling production of Norway spruce (Picea abies (L.) Karst.). Dissertationes Forestales

Högberg K, Bozhkov P, Grönroos R, Arnold SV (2001) Critical factors affecting ex vitro performance of somatic embryo plants of Picea abies. Scand J For Res 16:295-304

Huang S, Chan H, Wang T (2006) Induction of somatic embryos of celery by control of gaseous compositions and other physical conditions. Plant Growth Regul 49:219-227

Jansson G, Hansen JK, Haapanen M, Kvaalen H, Steffenrem A (2017) The genetic and economic gains from forest tree breeding programmes in Scandinavia and Finland. Scand J For Res 32:273286

Klimaszewska K, Cyr D, Sutton B (2000) Influence of gelling agents on culture medium gel strength, water availability, tissue water potential, and maturation response in embryogenic cultures of Pinus strobus L. In Vitro Cell Dev Biol - Plant 36:279-286

Klimaszewska K, Lachance D, Pelletier G, Lelu M, Séguin A (2001) Regeneration of transgenic Picea glauca, P. mariana, and P. abies after cocultivation of embryogenic tissue with Agrobacterium tumefaciens. In Vitro Cell Dev Biol - Plant 37:748-755

Kvaalen H, von Arnold S (1991) Effects of various partial pressures of oxygen and carbon dioxide on different stages of somatic embryogenesis in Picea abies. Plant Cell Tiss Org Cult 27:49-57

Litvay JD, Verma DC, Johnson MA (1985) Influence of a loblolly pine (Pinus taeda L.). Culture medium and its components on growth and somatic embryogenesis of the wild carrot (Daucus carota L.). Plant Cell Rep 4:325-328

Lelu M, Klimaszewska K, Pflaum G, Bastien C (1995) Effect of maturation duration on desiccation tolerance in hybrid larch (Larix $\times$ leptoeuropaea Dengler) somatic embryos. In Vitro Cell Dev Biol Plant 31:15-20

Mamun NH, Aidun CK, Egertsdotter U (2018) Improved and synchronized maturation of Norway spruce (Picea abies (L.) H. Karst.) somatic embryos in temporary immersion bioreactors. In Vitro Cell Dev Biol - Plant 54:612-620

Marini L, Økland B, Jönsson AM, Bentz B, Carroll A, Forster B, Grégoire J, Hurling R, Nageleisen LM, Netherer S (2017) Climate drivers of bark beetle outbreak dynamics in Norway spruce forests. Ecography 40:1426-1435

Morel A, Teyssier C, Trontin J, Eliášová K, Pešek B, Beaufour M, Morabito D, Boizot N, Le Metté C, Belal-Bessai L (2014) Early molecular events involved in Pinus pinaster Ait. Somatic embryo development under reduced water availability: transcriptomic and proteomic analyses. Physiol Plant 152:184-201
Ruotsalainen S (2014) Increased forest production through forest tree breeding. Scand J For Res 29:333-344

Salonen F, Varis S, Aronen T (2017) From Petri dishes to bioreactorsfirst experiences on optimization of Norway spruce SE-process for bioreactors. In: Park YS, Bonga JM (eds) Proceedings of the 4th international conference of the IUFRO unit 2.09.02. on Development and application of vegetative propagation technologies in plantation forestry to cope with a changing climate and environment, La Plata, Argentina, 19-23 Sept 2016, pp 293-297

SPSS (1999) Base 10.0 applications guide. 1st ed. Chicago, IL, SPSS Inc

Sun H, Aidun CK, Egertsdotter U (2010) Effects from shear stress on morphology and growth of early stages of Norway spruce somatic embryos. Biotechnol Bioeng 105:588-599

Sun H, Aidun CK, Egertsdotter U (2011) Possible effect from shear stress on maturation of somatic embryos of Norway spruce (Picea abies). Biotechnol Bioeng 108:1089-1099

Svobodová H, Albrechtová J, Kumstýrová L, Lipavská H, Vágner M, Vondráková Z (1999) Somatic embryogenesis in Norway spruce: anatomical study of embryo development and influence of polyethylene glycol on maturation process. Plant Physiol Biochem 37:209_ 221

Thompson D (2014) Challenges for the large-scale propagation of forest trees by somatic embryogenesis - a review. In: Park YS and Bonga JM (eds) Proceedings of the 3rd international conference of the IUFRO unit 2.09 .02 on Woody plant production integrating genetic and vegetative propagation technologies 8-12 Sept 2014. VitoriaGasteiz, Spain, pp 81-91

Tikkinen M, Varis S, Aronen T (2018a) Development of somatic embryo maturation and growing techniques of Norway spruce emblings towards large-scale field testing. Forests 9:325

Tikkinen M, Varis S, Peltola H, Aronen T (2018b) Improved germination conditions for Norway spruce somatic cotyledonary embryos increased survival and height growth of emblings. Trees 32:14891504

Tikkinen, M. A., Varis, S. A., Välimäki, S. M., Nikkanen, T. O., Aronen, T. S. (2019) Somatic embryogenesis of Norway spruce in Finlandseven years from start to first commercial pilots. In: Proceedings of the 5th international Conference of the IUFRO Unit 2.09. 02 on Clonal Trees in the Bioeconomy Age: opportunities and challenges /Bonga JM, Park YS, Trontin JF (eds.)

Varis S, Ahola S, Jaakola L, Aronen T (2017) Reliable and practical methods for cryopreservation of embryogenic cultures and cold storage of somatic embryos of Norway spruce. Cryobiol 76:8-17

Von Arnold S, Hakman I (1988) Regulation of somatic embryo development in Picea abies by abscisic acid (ABA). J Plant Physiol 132: 164-169

Welander M (2014) Plantform bioreactor. http://wwwplantformse/pub/ defaultaspx?p=100 Cited 9 Apr 2019

Welander M, Persson J, Asp H, Zhu L (2014) Evaluation of a new vessel system based on temporary immersion system for micropropagation. Scientia Hort 179:227-232 